\title{
Efficacy and Safety of Three Cryotherapy Devices for Wart Treatment: A Randomized, Controlled, Investigator-Blinded, Comparative Study
}

\author{
Imko Walczuk (D) - Frank Eertmans · Bart Rossel · Agnieszka Cegielska • \\ Eggert Stockfleth · Andre Antunes · Els Adriaens
}

Received: October 20, 2017 / Published online: December 6, 2017

(C) The Author(s) 2017. This article is an open access publication

\begin{abstract}
Introduction: Cutaneous warts are common skin lesions, caused by human papillomavirus. For years, liquid nitrogen is the cryogen of choice for wart treatment. Alternatively, several cryogenic devices for home treatment are commercially available. The present trial assessed efficacy and safety of a novel nitrous oxidebased cryogenic device for home use (EndWarts Freeze ${ }^{\circledR}$ in Europe, Compound $\mathrm{W}^{\circledR}$ Nitro-Freeze in the USA).

Methods: This investigator-blinded, controlled, randomized study compared the nitrous oxide device (test product) with a dimethylether propane-based product (Wartner ${ }^{\circledR}$; comparator 1). Subjects with common or plantar warts $(50 / 50$ ratio) were randomized into two groups ( $n=58$, test product; $n=40, \quad$ comparator 1$)$.
\end{abstract}

Enhanced content To view enhanced content for this article go to http://www.medengine.com/Redeem/ A6FCF0602ECF2F1F.

I. Walczuk - A. Cegielska

Dermscan Poland, Gdańsk, Poland

F. Eertmans $(\bowtie) \cdot$ B. Rossel · A. Antunes Oystershell Laboratories, Drongen, OVL, Belgium e-mail: frank.eertmans@oystershell.com

E. Stockfleth

St. Josef-Hospital, Bochum, Germany

E. Adriaens

Adriaens Consulting, Bellem, OVL, Belgium
Sequentially, an extra treatment arm $(n=40)$ was added to compare with a dimethyletherbased product with metal nib (Wortie ${ }^{\circledR}$; comparator 2). Main objective implied comparison of the percentage cured subjects after one to maximum three treatments. Efficacy and safety was evaluated by a blinded investigator.

Results: After a maximum of three applications, a significantly ( $p=0.001)$ higher cure rate of $70.7 \%$ (Intention-to-Treat analysis) was observed with test product versus $46.2 \%$ (comparator 1) and $47.5 \%$ (comparator 2). Almost three times more subjects were cured after 1 test product application (29.3\%), versus comparator $1(10.4 \%)$ and comparator 2 (12.5\%). Reported side effects were transient and typical of cryotherapy. All treatments were well-tolerated. Conclusion: The superior cure rates for the test product versus two comparators can be explained by its design. Combination of nitrous oxide (cooling agent), the specific activation method (holding the liquid coolant in the cap), and skin-conforming polyurethane foam, results in higher cooling efficiency $\left(-80^{\circ} \mathrm{C}\right)$ and more effective wart freezing. This trial demonstrated that the nitrous oxide device is a safe, user-friendly and effective wart treatment for home use, comparing favourably to dimethylether (propane) devices with higher freezing temperature, regardless of the applicator type.

Funding: Oystershell Laboratories. 
Trial Registration: Clinicaltrials.gov identifier, NCT03129373.

Keywords: Cryotherapy; Dimethylether (propane); Home treatment; Nitrous oxide; Prescription-free; Warts

\section{INTRODUCTION}

Cutaneous warts are common skin lesions, caused by different types of human papillomavirus (HPV) [1]. For years, cryotherapy with evaporating liquid nitrogen has been the therapy of choice to treat warts because of its clinical performance and the relatively minor and temporary adverse effects [2-9].

Cryotherapy relies on in-depth freezing and subsequent thawing of infected wart tissue. One of the theories behind the mode of action implies induction of local necrosis, resulting from this freeze-thaw cycle. Consequently, an immunoinflammatory process is initiated that makes the wart go into remission and cure $[10,11]$. As HPV infections are in the deeper epidermal layers, it is essential that cold is efficiently transferred to those layers during application. Several parameters influence the energy transfer, including the initial freezing temperature, the mode of application, treatment duration, and wart location [11-13].

Liquid nitrogen treatment achieves very low surface temperatures of $-196{ }^{\circ} \mathrm{C}$ and is solely used under a clinician's supervision to avoid unnecessary skin damage $[11,14]$. Alternatively, there are prescription-free cryogenic devices for home treatment of common or plantar warts. These devices freeze through evaporative cooling by sudden expansion of compressed solvents, such as the low boiling and flammable dimethylether (DME) and DME propane mixture (DMEP). Other possible coolants are liquefied, true gases are used such as carbon dioxide $\left(\mathrm{CO}_{2}\right)$ and nitrous oxide $\left(\mathrm{N}_{2} \mathrm{O}\right)$, which pose less fire risk and which are safer for the skin [16-18].

In the present randomized, controlled, investigator-blinded clinical study, efficacy and safety of a new cryogenic pen, based on nitrous oxide (known as EndWarts Freeze ${ }^{\circledR}$ in Europe and Compound $\mathrm{W}^{\circledR}$ Nitro-Freeze in the USA), was compared to Wartner ${ }^{\circledR}$ (DMEP-based). Both products have a comparable mode and duration of application. In both products, a polyurethane (PU) foam nib is frozen and applied to the wart. However, there is a substantial difference in the freezing temperature that both devices are capable to reach. Nitrous oxide boils at $-87^{\circ} \mathrm{C}$, in between the boiling point of liquid nitrogen $\left(-196^{\circ} \mathrm{C}\right)$ and DMEP $\left(-57^{\circ} \mathrm{C}\right)[11,16,17]$. In the past, several reports have questioned whether DMEP matches the clinical efficacy of liquid nitrogen. Considering that the homeotherm body is very competent in maintaining skin temperature around $29-31^{\circ} \mathrm{C}$ [18], the question arises indeed whether $\operatorname{DME}(\mathrm{P})$ based devices are cold enough for effective treatment of warts. A target temperature of $-50{ }^{\circ} \mathrm{C}$ at a depth of $4-5 \mathrm{~mm}$ is required to allow complete freezing of intracellular water and to initiate the necrotic cascade that is essential for wart shedding and healing [11].

Not only freezing temperature is a crucial parameter for clinical success, but also the type of skin applicator and its thermoconductive properties. Recent years have seen the introduction on the market of a DME $\left(-24^{\circ} \mathrm{C}\right)$ device with copper/brass nibs that are more thermoconductive than PU foam nibs [19]. For this reason, a theoretically better freezing performance is expected with metal nibs compared to the soft polyurethane nibs. This comparison has been addressed by annexing an extra treatment arm (Wortie ${ }^{\circledR}$, DME-based) to the study.

Although different manufacturers claim similar performance when compared to liquid nitrogen treatment, published clinical data remains scarce and is often contradictory $[15,20,21]$. This clinical trial was set-up to gain more insights into the clinical efficacy and safety of prescription-free, cryogenic devices.

\section{METHODS}

\section{Study Set-up}

This investigator-blinded, controlled, open label, comparative study was approved by an independent Ethics committee (Bioethical Committee at the Regional Medical Centre in 
Gdansk) on $25 / 06 / 2015$. The study was conducted in accordance with the principles of the Declaration of Helsinki 2013, Good Clinical Practice, and of the European Union Directive 2001/20/EC as well as the requirements of German drug law and data protection laws. The trial was registered at ClinicialTrial.gov (NCT03129373).

The study took place at a clinical trial facility, specialized in conducting dermatological clinical studies (Dermscan, Gdansk, Poland). Recruitment was performed by trained personnel and continued from July 2015 (first patient first visit) to November 2016 (last patient last visit). Initial study design (parallel, randomized) compared the clinical efficacy and safety of the nitrous oxide test product and the DMEP product Wartner ${ }^{\circledR}$ (further referred to as "comparator $1 "$ ).

The original protocol was adapted for some methodological reasons. First, in the therapeutic interest of patients with multiple warts, the investigators treated all warts but only one wart per patient was followed up for evaluation (protocol amendment 1). A second amendment of the protocol was related to the type of nib of the investigational device. The original investigational product was not yet equipped with the final soft polyurethane nib but with a hardsintered plastic point. All results discussed in this paper, howeve, are from the investigational product with the final PU nib. Thirdly, a solution had to be found for patients presenting a blister that barred retreatment, as planned on D15 or D29. In these cases, treatment (if required) was postponed to the earliest scheduled visit after healing of the blister (amendment 3). An additional issue with wart treatment studies implies that spontaneous recruitment often leads to over-representation of cases of plantar warts. To assure a balanced 1:1 distribution of hand and foot warts, 18 extra subjects with common warts on the hand were randomized in the study $(n=58$ in total; amendment 4). Finally, at the end of the parallel phase, the study was extended with a sequential group to evaluate the clinical performance of a third commercial product (Wortie $^{\circledR}$, further referred to as "comparator 2"), which is also DME-based but uses a metal nib instead of a soft PU nib (protocol amendment $5)$.

\section{Inclusion and Exclusion Criteria}

Subjects were recruited (1) by phone, based on registration files of people willing to participate to clinical studies at the CRO, (2) via advertisements on the CRO's website, and (3) by contacting patients from the Investigator's database. Inclusion and exclusion criteria are summarized in Fig. 1.

\section{Patients}

\section{Sample Size, Informed Consent, Randomization, and Baseline Data}

Based on previous available clinical data of comparators and other available therapies, an initial sample size of 78 subjects was calculated to allow correct statistical comparison between test product and comparator 1. Based on this information, 80 eligible subjects were recruited by the study staff and randomly allocated into two groups. Prior to the study, a randomization list was calculated using SAS software (version 9.4). Randomisation was performed using block randomisation (block size of 2). In the test product group, the ratio of hand/foot warts was initially not equal and 18 additional subjects with hand warts were additionally randomized.

Study participants or their legal representative in case of minors gave written consent and the children also provided written or verbal assent, per age, witnessed by the parent or guardian. Informed consent was obtained before any study-specific procedures were performed according to the Helsinki Declaration. Upon approval and signing, a subject screening number was assigned to each subject by the responsible investigator. If the consent to participate in the trial was withdrawn before randomisation or if the subject was not included, the subject number was kept and not reassigned to another subject. Baseline demographic data were collected on gender, age, phototype, type and localisation of the wart, frequency of wart apparition, and medical history. 

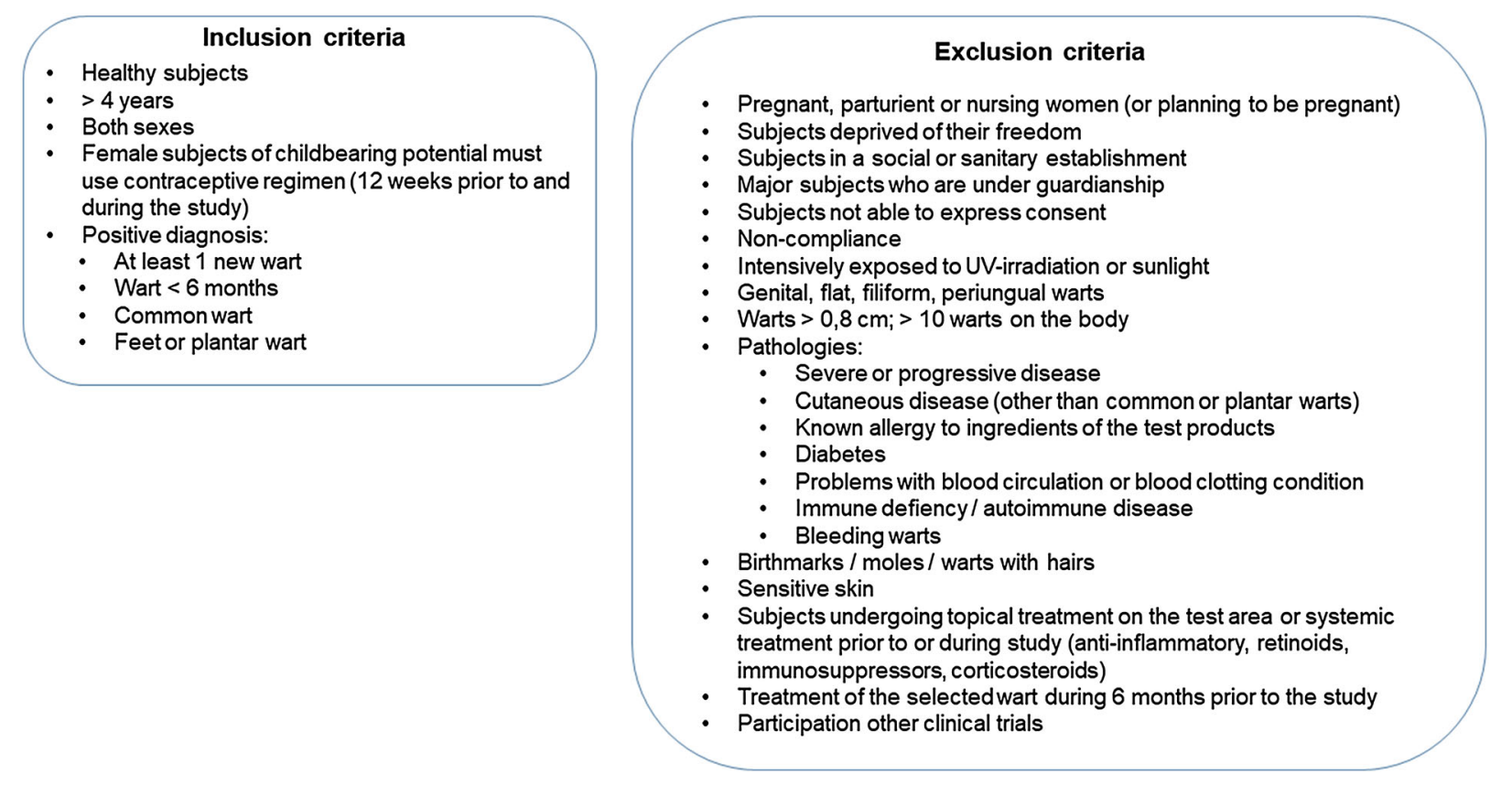

Fig. 1 Inclusion and exclusion criteria

As mentioned above, a new treatment arm was included into the study to evaluate clinical performance and safety of comparator 2 .

\section{Blinding}

Because the commercial products are so distinctly different, it made no sense to blind clinical staff or patients. To compensate for this treatment bias, the clinical evaluation at each time point was performed by blinded study staff. In addition, pictures were taken for later review.

\section{Study Medication, Dosage and Administration}

The test product contains a non-replaceable, non-refillable nitrous oxide $\left(\mathrm{N}_{2} \mathrm{O}\right)$ capsule in a dispensing device. Activation of the device delivers a dose of nitrous oxide liquid into the applicator, resulting in a cool down of the polyurethane (PU) foam nib to $-80^{\circ} \mathrm{C}$. Then the applicator tip is applied on the wart and freezes the epidermal tissue. Application was performed according to the instructions for use. Briefly, before first application, the pen is activated once by screwing at least one full turn until the indicator mark is back in the shaded zone. Next, the closed pen is put on a surface and held firmly with one hand. Using the other hand, the pen is pushed down for $2 \mathrm{~s}$ (a hissing sound is noticed). Then, the pen is removed from the cap (ice vapour will be present) and is applied firmly against the wart (15 s on hand warts, $40 \mathrm{~s}$ on feet and toes). Following application, the PU nib was discarded and replaced by a fresh one for the next treatment. According to the instructions for use, a new application can be performed at least 14 days after the first treatment in case the wart was not cured. Patients are advised to contact a physician if treatment failed (maximum of three treatments allowed). Comparator product 1 (Wartner; DMEP-based) is supplemented with a foam nib, which must be put on the stick of the applicator holder prior to use. Next, the holder and foam applicator are put into the opening on top of the aerosol can and are pressed firmly for $3 \mathrm{~s}$ (a hissing sound is noticed). Applicator holder with the foam applicator, soaked with DMEP, is removed and then applied lightly on the wart for a specific period, depending on wart diameter and location. For hands, an application time of $10 \mathrm{~s} \quad$ (diameter $<2.5 \mathrm{~mm}$ ), $15 \mathrm{~s}$ 
(2.5-5 mm), $20 \mathrm{~s}(>5 \mathrm{~mm})$, and $40 \mathrm{~s}$ on plantar warts, respectively, is recommended. Afterwards, the foam applicator can be discarded and replaced by a fresh one. According to the leaflet, a new product application may be performed at least 2 weeks after the first treatment, with a maximum of three applications. If the wart is not cured, a visit to a physician is advised.

Comparator product 2 (Wortie; DME-based) comes without a foam applicator but has a metal tip. The pen is activated by pressing $3 \mathrm{~s}$. Next, the metal tip is pressed firmly on the wart for $20 \mathrm{~s}$ (hand warts) or $40 \mathrm{~s}$ (feet warts), respectively. According to the instructions for use, a new application is performed after 2 weeks in case therapy failed, with a maximum of two treatments.

In total, a maximum of five visits and three treatments were planned for each subject. Briefly, at day 0 , following collection of baseline information, all subjects were treated with one of the test products. A first clinical evaluation (wart measurement, adverse event registration) was performed 3 days following the first treatment. Visits 3, 4, and 5 (if required) were planned on day (D) 15, 29, and 45 days, respectively. At these time points, wart remission was clinically evaluated and a new treatment was performed, if required. However, in some cases, skin healing did not allow for new application and treatment was postponed to the next time point. To facilitate data interpretation, reference is made to the number of visits and treatments, respectively.

\section{Patient Disposition}

Three populations have been included for statistical analyses: the Intention-to-Treat (ITTpopulation, the Per Protocol (PP) population, and the safety population, respectively.

The ITT population included all subjects which were randomized, as originally allocated according to the randomisation scheme, and which have at least one efficacy endpoint. In total, data on 137 subjects were included in the three treatment groups: $n=58$ (test product), $n=39$ (comparator group 1), and $n=40$ (comparator 2). One subject in the comparator group 1 was lost to follow-up after the baseline visit.
The PP population included all subjects that were cured after a maximum of three treatments, omitting subjects that were not cured after less than three treatments. In total, data on 124 subjects were included: $n=50$ (test product), 38 (comparator 1), and 36 (comparator 2), respectively.

The safety population included all subjects who received at least one treatment and that had a final assessment for tolerance. In total, data on 130 subjects were included in the three treatment groups: $n=55$ (test product), $n=39$ (comparator group 1), and $n=36$ (comparator 2).

\section{Efficacy Evaluation}

The primary objective implied comparison of the percentage of subjects with clinical wart remission after 1, 2 and 3 treatments with test product versus both comparators, as observed during a clinical evaluation of the treated wart by the dermatologist.

Secondary objectives included comparison of the number of treatments needed for clinical remission of warts with the three products. Surface area measurements of the frostbite were performed to assess efficacy of the freezing process during the three treatments (if applicable). Visual aspects of wart remission were illustrated with macrophotographs. Briefly, a Nikon D90 camera was combined with a repositioning system to standardize distance during photographing. Images were digitalized and recorded on a computer. Parameters for clinical evaluation of wart evolution/remission are presented in Table 1. A wart was considered cured if surface area measurements were near zero $\left(\mathrm{cm}^{2}\right)$ and if there was no presence of roughness and thickness of the skin. In case clear symptoms of the wart were present, a new treatment was performed (maximum of three). Efficacy of the freezing process was evaluated immediately after product application after first, second or third treatment (if applicable).

\section{Safety Evaluation}

Local tolerance on skin was assessed at the end of the study, considering abnormal clinical 
Table 1 Clinical parameters for evaluation of wart progression

\begin{tabular}{|c|c|}
\hline Clinical parameter & Score \\
\hline Wart diameter & Size $(\mathrm{mm})$ \\
\hline Roughness & $\begin{array}{l}\text { 0: none, } 1: \text { light, } 2: \text { moderate, } 3 \text { : } \\
\text { severe, } 4: \text { very severe }\end{array}$ \\
\hline $\begin{array}{l}\text { Wart thickness } \\
\text { (common warts) }\end{array}$ & $\begin{array}{l}\text { 0: absence, } 1 \text { : light, } 2 \text { : moderate, } 3 \text { : } \\
\text { severe, } 4: \text { very severe }\end{array}$ \\
\hline $\begin{array}{l}\text { Discontinuation of } \\
\text { skin lines }\end{array}$ & $\begin{array}{l}\text { 0: absence, } 1 \text { : light, } 2: \text { moderate, } 3 \text { : } \\
\text { severe; } 4 \text { : very severe }\end{array}$ \\
\hline Skin colour & $\begin{array}{l}\text { 0: none, } 1: \text { light, } 2 \text { : moderate, } 3 \text { : } \\
\text { severe; } 4: \text { very severe }\end{array}$ \\
\hline Product efficacy & $\begin{array}{l}\text { 1: Not efficient, 2: rather not } \\
\text { efficient, 3: rather efficient, 4: } \\
\text { efficient, 5: very efficient }\end{array}$ \\
\hline
\end{tabular}

signs and subjective signs reported by the patients. According to these signs, local tolerance of the product was scored using the following scale: $0=$ bad tolerance, $1=$ moderate tolerance, 2 =good tolerance, and $3=$ very good tolerance. Global tolerance was assessed by recording adverse reactions and events.

\section{Statistical Analyses}

All analyses were performed by an independent statistician. The initial protocol only included a PP population and safety population analysis. A post hoc analysis was performed on the ITT population.

Continuous data were summarized by their mean, standard deviation, median, minimum and maximum. Categorical data were summarized by frequencies and percentages.

The Chi square test for independence was used to compare the cured versus not cured number of subjects, after a maximum of three treatments, between the test product, comparator 1 and comparator 2-treated subjects, respectively. All descriptive and statistical analyses were performed in $\mathrm{R}$ version 3.3.0. ( $\mathrm{R}$ development core team, 2016). A $p$ value $<0.05$ was considered as statistically significant. No imputation of missing data was performed. The amount of missing data is presented in the tables wherever appropriate.

\section{RESULTS}

\section{Baseline Patient Characteristics}

Study data were collected between July 2015 and November 2016. In total, 142 subjects were screened. Four subjects did not meet the inclusion criteria and thus, 138 subjects were randomized into the study. One person in the comparator 1 group withdrew consent during the first visit and thus, 137 subjects received first study treatment $(n=58$, test product; $n=39$; comparator 1 ; $n=40$ : comparator 2 ).

Two subjects from the test product group were lost to follow-up and one subject withdrew his consent after first treatment. Another five subjects from the test product group received only two treatments and were not cured. One subject from the comparator 1 group was lost to follow-up after baseline visit. Another subject from this treatment group did receive only two treatments and was not cured. Four subjects of the comparator 2 group were lost to follow-up and received only one or two treatments. A CONSORT flow chart for the ITT and PP analyses is shown in Figs. 2 and 3, respectively.

Baseline data on average age ( \pm standard error of the mean (SEM)), gender, phototype, type of wart (common/plantar) and frequency of wart apparition are summarized in Table 2. In the test product group, 50\% (29/58) of the subjects were treated for a plantar wart. This was similar to the comparator 1 group $(48.7 \%$; 19/39) and the comparator 2 group (52.5\%; $21 / 40)$, respectively. All values were within the randomization criteria.

\section{Primary Efficacy Endpoint}

Treatment efficacy of the test product versus both comparators was evaluated in terms of the number of treatments, needed to be cured. Table 3 provides a summary of the number of subjects that were cured after each treatment or that were not cured after a maximum of three 


\begin{tabular}{|c|c|c|c|c|}
\hline Enrollment & \multicolumn{2}{|c|}{ Assessed for eligibility $(n=142)$} & & \\
\hline & $\longrightarrow$ & \multicolumn{2}{|c|}{$\begin{array}{l}\text { Excluded }(n=4) \\
\text { : Not meeting inclusion criteria }(n=4) \\
\text { - Oeclined to participate }(n=0) \\
\text { Other reasons }(n=0)\end{array}$} & \\
\hline \multicolumn{5}{|c|}{ Randomized $(n=138)$} \\
\hline \multicolumn{5}{|l|}{$\downarrow$} \\
\hline $\begin{array}{l}\text { Test product } \\
\text { Allocated to intervention }(n=58) \\
\text { - Received allocated intervention }(n=58) \\
\text { - Did not receive allocated intervention } \\
(n=0)\end{array}$ & \multicolumn{2}{|c|}{$\begin{array}{l}\text { Comparator } 1 \\
\text { Allocated to intervention }(n=40) \\
\text { - Received allocated intervention }(n=39) \\
\text { - Did not receive allocated intervention } \\
(n=1 ; \text { withdrawal of consent at baseline) }\end{array}$} & \multicolumn{2}{|c|}{$\begin{array}{l}\quad \text { Comparator } 2 \\
\text { Allocated to intervention }(n=40) \\
\text { - Received allocated intervention }(n=40) \\
\text { - Did not receive allocated intervention } \\
(n=0)\end{array}$} \\
\hline \multicolumn{5}{|l|}{ Follow-up } \\
\hline $\begin{array}{l}\text { Lost to follow-up ( } n=2 \text {; after } 1 \text { or } 2 \text { treatm.) } \\
\text { Discontinued intervention ( } n=6 \text { : } n=5 \text { : only } 2 \\
\text { treatments and subjects were not cured; } 1 \\
\text { withdrawal of consent; ) }\end{array}$ & \multicolumn{2}{|c|}{$\begin{array}{l}\text { Lost to follow-up ( } n=0) \\
\text { Discontinued intervention ( } n=1 \text {; only } 2 \\
\text { treatments and subject was not cured) }\end{array}$} & \multicolumn{2}{|c|}{$\begin{array}{l}\text { Lost to follow-up ( } n=4 ; 1 \text { from D29; } 3 \text { from } \\
\text { D45) } \\
\text { Discontinued intervention }(n=0)\end{array}$} \\
\hline \multicolumn{5}{|l|}{ Analysis } \\
\hline $\begin{array}{l}\text { Analyzed }(n=58) \\
\text { - Excluded from analysis }(n=0)\end{array}$ & \multicolumn{2}{|l|}{$\begin{array}{l}\text { Analyzed }(n=39) \\
\text { - Excluded from analysis }(n=0)\end{array}$} & $\begin{array}{l}\text { Analyzed }(n=40) \\
\text { - Excluded from analys }\end{array}$ & is $(n=0)$ \\
\hline
\end{tabular}

Fig. 2 CONSORT flow chart (ITT population)

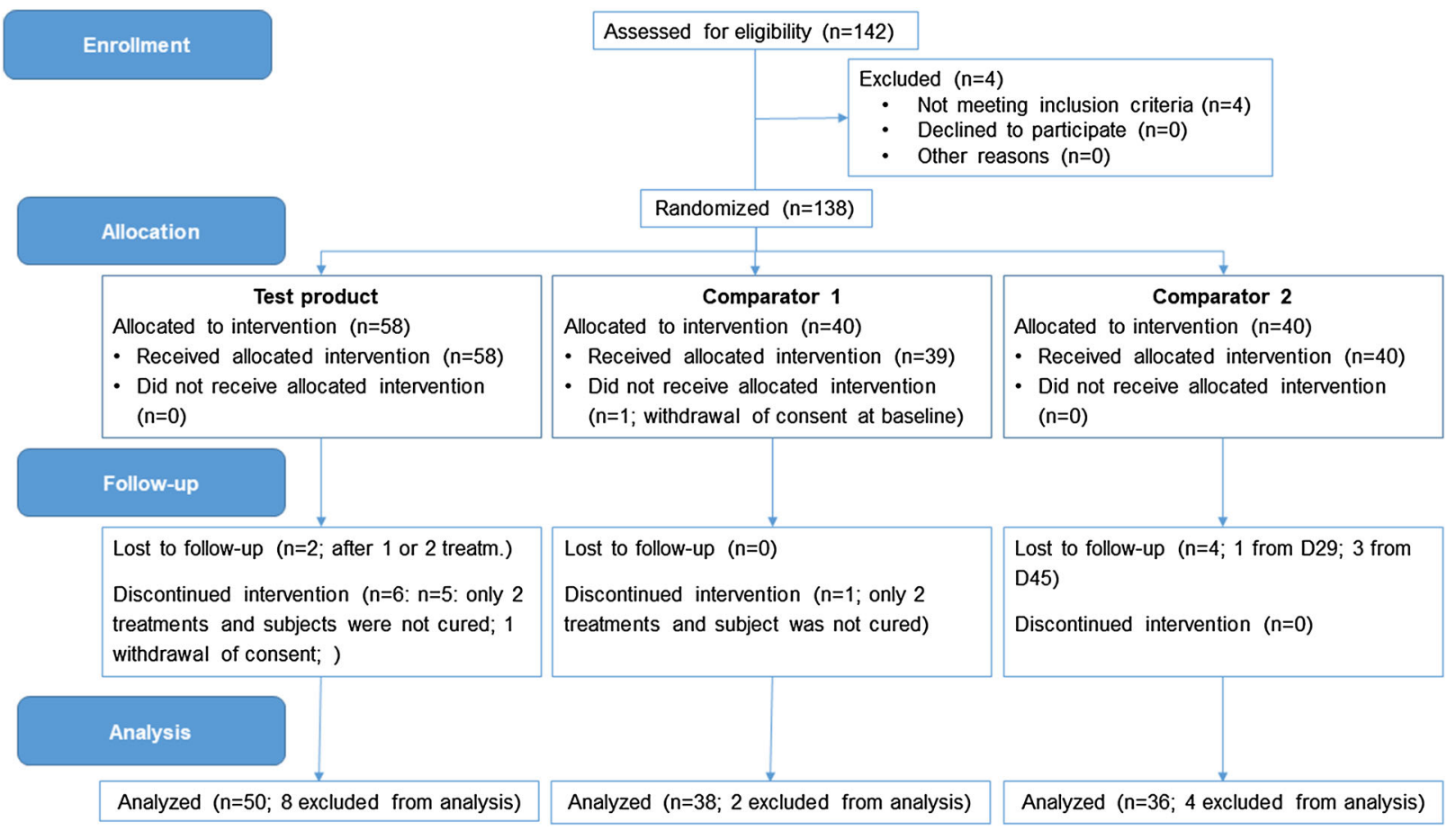

Fig. 3 CONSORT flow chart (PP population) 
Table 2 Baseline characteristics of recruited subjects

\begin{tabular}{llllll}
\hline & Age $( \pm$ SEM) & Gender & Wart type & Phototype & Frequency wart apparition \\
\hline Test product & $32 \pm 2(5-68)$ & F: 39 & Common: 29 & I: 2 & Very often: 0 \\
& M: 19 & Plantar: 29 & II: 46 & Often: 12 \\
& & & III: 10 & Rarely: 20 \\
Comp. 1 & & & & First time: 26 \\
& & & & Very often: 0 \\
& & F: 22 & Common: 20 & I: 1 & Often: 4 \\
Comp. 2 & M: 17 & Plantar: 19 & II: 30 & Rarely: 12 \\
& & & III: 8 & First time: 23 \\
& & & & Very often: 1
\end{tabular}

Table 3 Number of treatments needed for cure (ITT and PP populations)

\begin{tabular}{|c|c|c|c|c|c|c|c|c|}
\hline \multirow[t]{2}{*}{ Treatment } & \multicolumn{6}{|c|}{ Cured after $X$ treatments } & \multicolumn{2}{|c|}{$\begin{array}{l}\text { Not cured after three } \\
\text { treatments }\end{array}$} \\
\hline & $X=1$ ITT & $X=1 \mathrm{PP}$ & $X=2$ ITT & $X=2 \mathrm{PP}$ & $X=3$ ITT & $X=3 \mathrm{PP}$ & ITT & PP \\
\hline Test product & $\begin{array}{l}29.3 \% \\
\quad(17 / 58)\end{array}$ & $\begin{array}{l}34.0 \% \\
\quad(17 / 50)\end{array}$ & $\begin{array}{l}24.1 \% \\
\qquad(14 / 58)\end{array}$ & $\begin{array}{l}28.0 \% \\
\qquad(14 / 50)\end{array}$ & $\begin{array}{l}17.2 \% \\
\quad(10 / 58)\end{array}$ & $\begin{array}{l}20.0 \% \\
\qquad(10 / 50)\end{array}$ & $\begin{array}{l}29.3 \% \\
\quad(17 / 58)\end{array}$ & $\begin{array}{l}18.0 \% \\
\quad(9 / 50)\end{array}$ \\
\hline Comp. 1 & $\begin{array}{l}10.4 \% \\
(4 / 39)\end{array}$ & $\begin{array}{l}10.5 \% \\
(4 / 38)\end{array}$ & $\begin{array}{l}17.9 \% \\
(7 / 39)\end{array}$ & $\begin{array}{l}18.4 \% \\
(7 / 38)\end{array}$ & $\begin{array}{l}17.9 \% \\
(7 / 39)\end{array}$ & $\begin{array}{l}18.4 \% \\
(7 / 38)\end{array}$ & $\begin{array}{l}53.8 \% \\
(21 / 39)\end{array}$ & $\begin{array}{l}52.6 \% \\
(20 / 38)\end{array}$ \\
\hline Comp. 2 & $\begin{array}{l}12.5 \% \\
(5 / 40)\end{array}$ & $\begin{array}{l}13.9 \% \\
(5 / 36)\end{array}$ & $\begin{array}{l}7.5 \% \\
(3 / 40)\end{array}$ & $\begin{array}{l}8.3 \% \\
(3 / 36)\end{array}$ & $\begin{array}{l}27.5 \% \\
\qquad(11 / 40)\end{array}$ & $\begin{array}{l}30.6 \% \\
(11 / 36)\end{array}$ & $\begin{array}{l}52.5 \% \\
(21 / 40)\end{array}$ & $\begin{array}{l}47.2 \% \\
\quad(17 / 36)\end{array}$ \\
\hline
\end{tabular}

treatments in the ITT population and PP population, respectively.

In the ITT population, significantly $\left(\chi^{2}=7.8\right.$, $p=0.020)$ more subjects $(70.7 \%, 41 / 58)$ were cured after a maximum of three treatments with test product versus comparator 1 (46.2\%, 18/39), and comparator 2 (47.5\%, 19/40), respectively. The high cure rate was even more pronounced in the PP population, with $82 \%$ $(41 / 50)$ of all subjects, cured after a maximum of three applications of test product. This difference was significant $\left(\chi^{2}=13.3, p=0.001\right)$ when compared to the comparator 1 group
$(47.4 \% ; 18 / 38)$ and the comparator 2 group $(52.8 \% ; 19 / 36)$, respectively. Furthermore, in the ITT population, significantly $\left(\chi^{2}=7.0\right.$, $p=0.029)$ more subjects from the test product group (29.3\%) were cured after one treatment, compared to $10.4 \%(4 / 39)$ and $12.5 \%(5 / 40)$ in the comparator 1 group and in the comparator 2 group, respectively. This was also confirmed in the PP population, where $34 \%(17 / 50)$ of the treated subjects were cured after one treatment. The difference with the cure rates, observed in the comparator 1 group $(10.5 \% ; 4 / 38)$ and in the comparator 2 group (13.9\%; 5/36), 
respectively, was statistically significant $\left(\chi^{2}=8.7, p=0.013\right)$.

Treatment efficacy was scored from not efficient (no improvement) to very efficient (total cure) by an investigator after each visit. The higher cure rate, observed in the test product group, was also reflected by the investigator's opinion on product efficacy in both ITT and PP populations. During the last visit, the test product was found to be very efficient for $65.5 \%$ (38/58; ITT)/76\% (38/50; PP) of the subjects, whereas very efficient was observed for $38.5 \%$ $(15 / 39$; ITT)/39.5\% (15/38; PP) of the subjects in the comparator 1 group and for $47.5 \%(19 / 40$; ITT) $/ 52.6 \%$ (19/36; PP) of the subjects in the comparator 2 group. This difference in efficacy was significant $\left(\chi^{2}=7.4, p=0.024\right)$. One subject from the test product group was not completely cured but received a score of 5 (very efficient) after the third treatment. Indeed, wart diameter was indeed very small $(0.09 \mathrm{~cm})$, indicating that the wart had almost disappeared.

\section{Secondary Efficacy Endpoints}

\section{Wart Diameter}

Wart diameter in subjects who were not cured, gradually decreased as a function of the number of treatments. No significant differences were observed between the three treatment groups. Similar observations were made for the PP population.

\section{Roughness}

Reduction of wart roughness is an important indicator for wart remission/curing. When compared to baseline, a gradual increase in \% of subjects, showing no roughness (score $=0$ ), was observed in the test product group, with 50\% $(10 / 20)$ of the subjects showing no roughness after three treatments. This was remarkably lower in the comparator 1 group $(25.9 \% ; 7 / 27)$ and in the comparator 2 group (28.6\%; 8/28), respectively. Similar observations were made in the PP population.

\section{Thickness (Common Warts)}

Thickness of common warts is an important clinical parameter to evaluate wart evolution. In the ITT population, a gradual increase in \% of subjects in the test product group, showing absence of thickness (score $=0$ ), was observed. After three treatments, $71.4 \%(5 / 7)$ of the remaining subjects was assigned a score of 0 for thickness. This was remarkably lower in the comparator 1 group $(15.4 \% ; 2 / 13)$ and the comparator 2 group $(30.8 \% ; 4 / 13)$, respectively. Similar observations were made in the PP population.

\section{Discontinuation of Skin Lines}

The presence of a wart mostly results in disruption of the skin lines. This is also reflected by the baseline data, where discontinuation of skin lines was present in $97.4 \%$ (comparator 1 group) and $100 \%$ (test product and comparator 2 group, respectively) of the subjects. In the test product group, a gradual increase of subjects, showing no discontinuation of skin lines, was observed. After three treatments, discontinuation of skin lines was absent in $45 \%(9 / 20)$ of the subjects in the test product group. This was substantially lower in the comparator 1 group $(25.9 \% ; 7 / 27)$ and the comparator 2 group $(32.1 \%$; 9/28). Similar observations were made in the PP population.

\section{Affection of Skin Colour}

The presence of warts may affect skin colour. At baseline, almost all subjects in the three treatment groups showed this phenomenon. The percentage of subjects with affected skin colour reduced as a function of the number of treatments when compared to baseline. No significant difference was observed among treatment groups.

\section{Frost Bite Diameter}

After each treatment, the average frostbite diameter was comparable in both test product and comparator 1 groups. Diameter was lower in the comparator 2 group, but no significant differences were found among treatment groups. Data of ITT population are summarized 
Table 4 Summary statistics of the diameter of the frostbite as a function of number of treatments

\begin{tabular}{lllll}
\hline Treatment & Statistic & Diameter frostbite & \\
\cline { 3 - 4 } & & After one TRT & After two TRT's & After three TRT's \\
\hline Test product & $N$ & 58 & 39 & 19 \\
& Mean \pm SD, cm & $0.676 \pm 0.208$ & $0.654 \pm 0.278$ & $0.66 \pm 0.251$ \\
& Range, cm & $0.104 ; 1.086$ & $0 ; 1.184$ & $0.172 ; 1.044$ \\
Comparator 1 & $N$ & 39 & 35 & 27 \\
& Mean \pm SD, cm & $0.671 \pm 0.328$ & $0.55 \pm 0.287$ & $0.663 \pm 0.271$ \\
& Range, cm & $0 ; 1.7$ & $0 ; 1.413$ & $0.18 ; 1.149$ \\
Comparator 2 & $N$ & 40 & 35 & 29 \\
& Mean \pm SD, cm & $0.521 \pm 0.153$ & $0.484 \pm 0.159$ & $0.531 \pm 0.147$ \\
& Range, cm & $0 ; 0.841$ & $0.2 ; 0.883$ & $0.253 ; 0.897$ \\
\hline
\end{tabular}

in Table 4. Similar results were seen in the PP population.

\section{Safety and Tolerance Evaluation}

The adverse events, reported following treatment with all test products, are comparable to those observed with cryotherapy of warts, and last for only a few days following treatment. Anticipated skin response events such as blistering, superficial pain and a transient burning sensation were the most frequent adverse events. These were in line with the expectations and predictive for wart removal outcome and the number of treatments required. Indeed, a lower number of cryotherapy-related side effects was reported following application of both comparator products. In total, 10, 16, and 29 adverse events were not linked to treatment with test product, comparator 1 and 2, respectively. One serious adverse event (hemiplegic migraine) was reported in the comparator 1 group but was not related to the cryogenic treatment.

Local tolerance of the treatment was assessed by the investigator at the end of the therapy. In general, all products were well tolerated. In the test product group tolerance was low or moderate for 3 and 2 subjects, respectively. However, for those subjects, a very good efficiency score was given, indicating that the wart was cured. Very good tolerance was observed for $82.1 \%$ and $86.1 \%$ of the subjects for comparator 1 and 2, respectively. However, only $47.4 \%$ and $52.8 \%$ of those subjects were cured, respectively. In the test product group, very good tolerance was observed in the majority $(56.4 \%)$ of the subjects and for $71 \%$ of those subjects, the product was found to be very efficient. These data suggest that the tolerance score is a measure for the anticipated skin response (redness and a therapeutic blister), being predictive of efficacious wart removal in the test product group.

\section{DISCUSSION}

The present open label, randomized, controlled, investigator-blinded study revealed high cure rates after one or more applications of the nitrous oxide cryogenic pen for home treatment of warts. Comparison was made of two commercial cryogenic devices, using either DME or DMEP as cooling agent. In both ITT and PP populations, significantly higher cure rates were observed with the test product after a maximum of three treatments. In total, $70.7 \%$ (ITT) $/ 82 \%$ (PP) of the subjects were cured in the test group, in contrast to $46.2 \%$ (ITT) $/ 47.4 \%$ (PP) in the comparator 1 group and $47.5 \%$ (ITT) $/ 52.8 \%$ (PP) 
in the comparator 2 group, respectively. After only one treatment, nearly threefold of all subjects in the test product group were cured when compared to treatment with both comparators. Clinical efficacy was further supported by the efficiency scores, as assigned by a blinded investigator. The number of subjects, receiving a score "very efficient" was significantly higher following treatment with test product versus comparators. Other wart-related clinical parameters, including roughness, thickness, and discontinuation of skin lines, also improved significantly as a function of the number of treatments. In subjects who were not cured after a maximum of three treatments, a gradual decrease of wart diameter was observed as a function of the number of applications in all treatment groups. However, after each treatment, no significant difference in decrease was observed among the three treatment groups.

Clinical efficacy of cryotherapy devices depends on several factors, including the type of wart and the mode of application: spray versus contact applicator, freezing time, freezing technique, and lag time between treatments ( 1 to 4 weekly intervals). In general, each wart is frozen for 10-30 s until a 1-2 $\mathrm{mm}$ ice ball halo surrounds the wart area. The best results are achieved when treatments are done every 2 or 3 weeks [11-13]. In the present trial, distribution of the type of wart was comparable among treatment groups. Also, application time was identical or similar for all products.

Wart treatment guidelines [22-24] advise to treat both surrounding healthy skin and wart until an ice ball halo of $1-2 \mathrm{~mm}$ around the wart is obtained. Data of the present study suggest that a soft type of nib that envelops some surrounding skin is preferred above hard variants, as used in comparator 2 (metal nib). Indeed, following treatment with comparator 2 , a trend to lower frostbite diameters was observed, suggesting that the metal nib does not ensure optimal skin contact when compared to a foam nib.

Earlier research demonstrated that a temperature of $-50{ }^{\circ} \mathrm{C}$ at a depth of $4-5 \mathrm{~mm}$ is required for optimal wart treatment [11]. Therefore, initial temperature of the applicator of the cryogenic device must be low enough to achieve such temperature in the lower layers of the infected area. The concept of the test product, combining a specific polyurethane nib as applicator, guaranteeing optimal skin contact, and nitrous oxide as cooling agent, allows the device to reach an in vitro freezing temperature of $-80^{\circ} \mathrm{C}$, which can be maintained for a period of $60 \mathrm{~s}$. This temperature lies between the boiling point of liquid nitrogen $\left(196{ }^{\circ} \mathrm{C}\right)$ and the boiling point of the gases, used in the comparator devices: DME $\left(-24^{\circ} \mathrm{C}\right)$ and DMEP $\left(-57^{\circ} \mathrm{C}\right)$, respectively $[11,16,17]$. The significant difference in temperature may explain why the comparator products showed lower cure rates in the present trial. In addition, the different type of nib, as applied in comparator 2, may further reduce product efficacy, as discussed above.

A variety of adverse effects with cryotherapy of warts have been previously reported, including pain during application, erythema, (haemorrhagic) blister formation, depigmentation, and recurrence of the wart [2-7]. Because of the significantly lower temperature of the test product, the number of subjects who reported cryotherapy-related side effects (blistering, burning sensation, superficial pain) was higher when compared to subjects, treated with the comparators. However, these expected and temporary effects confirmed that the observed skin response following application is an indicator for efficient wart removal in the test product group. In general, all subjects tolerated the cryotherapy well in all treatment groups.

One can speculate that these side effects may have a negative impact on product compliance. However, cryotherapy-related side effects are only temporary. Furthermore, the tested cryogenic devices are easy to use and may only be applied once to a maximum of three times, with a biweekly interval between each application. Also, the low number of applications, required to cure the wart (especially in case of the test product), is an advantage over alternative home therapies (e.g., keratinolytic agents, acid-based products...). Indeed, the latter require a daily application for a longer period (several weeks). Although these products have a good safety profile [25], therapy-specific side effects may 
also occur (e.g., skin irritation, burning or itching sensation, blistering, redness...) [26].

The present study clearly demonstrates that the nitrous oxide-based product performs significantly better than its DME(P)-based competitors. Although the study is robust and welldesigned, there are some limitations. First, the high cure rates, obtained with the test device, may not only be related to its design. Indeed, all treatments were performed by professional dermatologists. Cure rates may be lower when the cryogenic device is administered by consumers. However, this is applicable for all overthe-counter cryogenic treatments. Another limitation of the study is that only home use devices were considered: a comparison with liquid nitrogen could have been very productive but beyond the ambit of this study which was focused on consumer self-treat options. Clinical data on the performance of home use devices is scarce and thus, present trial results will further contribute to the field of cryotherapy of warts. Another limitation may be the number of subjects, included in this study. However, in view of cure rates after one to three treatments, significant differences were observed between the test product and the comparators. For other parameters, where no significant differences were found, positive trends were observed in favour of the test product. In other words, increasing the number of test subjects will normally result in decreased p-values and further strengthen observed trends.

\section{CONCLUSIONS}

In conclusion, significantly higher cure rates were obtained following one to three treatments with a nitrous oxide cryogenic device, when compared to two commercial cryogenic pens, using DME or DMEP as cooling agent. The combination of nitrous oxide as cooling agent, a soft applicator and a convenient design appears to contribute to an effective freezing of warts. Moreover, nitrous oxide is less flammable than dimethyl ether with or without propane, it is generally less toxic, and has been approved for medical use for a long time.
The present trial indicated that the test product is a safe, available and effective wart treatment, superior to $\mathrm{DME}(\mathrm{P})$ devices and this irrespective of the type of applicator.

\section{ACKNOWLEDGEMENTS}

Funding. Sponsorship for this study and article processing charges were funded by Oystershell Laboratories, that is also the manufacturer of the investigational product and employer of the co-authors Frank Eertmans, André Antunes, and Bart Rossel. The sponsor was involved in the study planning as well as in the decision to publish, but was not involved in data collection, data analysis and data interpretation.

Authorship. All named authors meet the International Committee of Medical Journal Editors (ICMJE) criteria for authorship for this manuscript, take responsibility for the integrity of the work as a whole, and have given final approval for the version to be published. All authors had full access to all data in this study and take complete responsibility for the integrity of the data and accuracy of the data analysis.

Medical Writing and/or Other Assistance. Oystershell Laboratories engaged the CRO Dermscan Poland (Gdansk, Poland) to independently design and perform the study. Co-author Imko Walczuk, who performed the clinical trial in cooperation with Agnieszka Cegielska (principle investigator) was responsible for patient investigation/recruitment/treatment and data collection. Statistical analyses were performed by an independent, external consultant, Els Adriaens (Adriaens Consulting, Bellegem, Belgium).

Disclosures. Frank Eertmans is an employee of the company Oystershell, who is the manufacturer of the test product and that funded this study. André Antunes is an employee of the company Oystershell, that is the manufacturer 
of the test product and that funded this study. Bart Rossel is an employee of the company Oystershell, that is the manufacturer of the test product and that funded this study. Imko Walczuk is a clinical investigator, associated with Dermscan Poland, who performed the study. Agnieszka Cegielska is a clinical investigator, associated with Dermscan Poland, who performed the study. Eggert Stockfleth and Els Adriaens have nothing to disclose.

Compliance with Ethics Guidelines. All procedures followed were in accordance with the ethical standards of the responsible committee on human experimentation (institutional and national) and with the Helsinki Declaration of 1964, as revised in 2013. Informed consent was obtained from all patients for being included in the study.

Data Availability. Datasets generated during and/or analyzed during the current study are not publicly available because all relevant clinical results, necessary to make correct conclusions, are presented in the publication. Data are available from the corresponding author on reasonable request.

Open Access. This article is distributed under the terms of the Creative Commons Attribution-NonCommercial 4.0 International License (http://creativecommons.org/licenses/ by-nc/4.0/), which permits any noncommercial use, distribution, and reproduction in any medium, provided you give appropriate credit to the original author(s) and the source, provide a link to the Creative Commons license, and indicate if changes were made.

\section{REFERENCES}

1. Tschandl P, Rosendahl C, Kittler H. Cutaneous human papillomavirus infection: manifestations and diagnosis. Curr Probl Dermatol. 2014;45:92-7.

2. Ahmed I, Agarwal S, Ilchyshyn A, Charles-Holmes $\mathrm{S}$, Berth-Jones J. Liquid nitrogen cryotherapy of common warts: cryo-spray vs. cotton wool bud. Br J Dermatol. 2001;144:1006-9.
3. Dall'oglio F, D'Amico V, Nasca MR, Micali G. Treatment of cutaneous warts: an evidence-based review. Am J Clin Dermatol. 2012;13:73-96. https://doi.org/10.2165/11594610-00000000000000 .

4. Cooper SM, Dawber RP. The history of cryosurgery. J R Soc Med. 2001;94:196-201.

5. Freiman A, Bouganim N. History of cryotherapy. Dermatol Online J. 2005;11:9.

6. Bruggink SC, Gussekloo J, Berger MY, Zaaijer K, Assendelft WJ, de Waal MW, et al. Cryotherapy with liquid nitrogen versus topical salicylic acid application for cutaneous warts in primary care: randomized controlled trial. CMAJ. 2010;182:1624-30. https:// doi.org/10.1503/cmaj.092194.

7. Steele K, Irwin WG. Liquid nitrogen and salicylic/ lactic acid paint in the treatment of cutaneous warts in general practice. J R Coll Gen Pract. 1988;38:256-8.

8. Berth-Jones J, Hutchinson PE. Modern treatment of warts: cure rates at 3 and 6 months. Br J Dermatol. 1992;127:262-5.

9. Erkens AMJL, Kuijpers RJAM, Knottnerus JA. Treatment of verrucae vulgares in general practice: a randomized controlled trial on the effectiveness of liquid nitrogen and the Histofreezer. J Dermatol Treat. 1992;3:193-6.

10. Krunic AL. Theoretical principles of immunocryosurgery. In: Pasquali P, editor. Cryosurgery: a practical manual. Berlin: Springer-Verlag; 2014. p. 33-48.

11. Andrews MD. Cryosurgery for common skin conditions. Am Fam Physician. 2004;69:2365-72.

12. Buckley D. Cryotherapy for warts. In: Pasquali P, editor. Cryosurgery: a practical manual. Berlin: Springer-Verlag; 2014. p. 107-19.

13. Dawber RPR, Colver G, Pringle F, Jackson A. Cutaneous cryosurgery: principles and clinical practice. 2nd ed. London: Martin Dunitz; 1997. p. 28-36.

14. Yiu W, Basco MT, Aruny JE, Cheng SWK, Sumpio BE. Cryosurgery: a review. Int J Angiol. 2007;16:1-6.

15. Burkhart CG, Pchalek I, Adler M, Burkhart CN. An in vitro study comparing temperatures of over-thecounter wart preparations with liquid nitrogen. J Am Acad Dermatol. 2007;57:1019-20.

16. Winkler JL, Jeronimo J, Singleton J, Janmohamed A, Santos C. Performance of cryotherapy devices using nitrous oxide and carbon dioxide. Int J Gynaecol Obstet. 2010;111:73-7. 
17. Maiti H, Cheyne MF, Hobbs G, Jerai HA. Cryotherapy gas-to use nitrous oxide or carbon dioxide. Int J STD AIDS. 1999;10:118-20.

18. Costello JT, Culligan K, Selfe J, Dennelly AE. Muscle, skin and core temperature after $-110^{\circ} \mathrm{C}$ cold air and $8^{\circ} \mathrm{C}$ water treatment. PLoS One. 2012; 7:e48910.

19. Thermal conductivity of common materials and gases. Available from: http://www. engineeringtoolbox.com/thermal-conductivity-d_ 429.html. Accessed Nov 2017.

20. Caballero Martínez F, Plaza Nohales C, Pérez Canal C, Lucena Martín MJ, Holgado Catalán M, Olivera Cañadas G. Cutaneous cryosurgery in family medicine: dimethyl ether-propane spray versus liquid nitrogen. Aten Primaria. 1996;18:211-6.

21. Nguyen NV, Burkhart CG. Cryosurgical treatment of warts: dimethyl ether and propane versus liquid nitrogen-case report and review of the literature. J Drugs Dermatol. 2011;10:1174-6.
22. Sterling JC, Handfield-Jones S, Hudson PM. Guidelines for the management of cutaneous warts. Br J Dermatol. 2001;144:4-11.

23. Gibbs S, Harvey I, Sterling JC, Stark R. Local treatments for cutaneous warts. Cochrane Database Syst Rev. 2004;4:CD001781.

24. Bacelieri R, Johnson SM. Cutaneous warts: an evidence-based approach to therapy. Am Fam Physician. 2005;72:647-52.

25. Bencini PL, Guida S, Cazzaniga S, Pellacani G, Galimberti MG, Bencini M, Naldi L. Risk factors for recurrence after successful treatment of warts: the role of smoking habits. J Eur Acad Dermatol Venereol. 2017;31:712-6.

26. Sultana R, Alam M, Khondker L, Ahamed RS. Safety in use of cryotherapy and topical salicylic acid with lactic acid combination in treating verruca vulgaris. Mymensingh Med J. 2012;21:715-22. 